\title{
The role of oxidative stress on the pathophysiology of metabolic syndrome
}

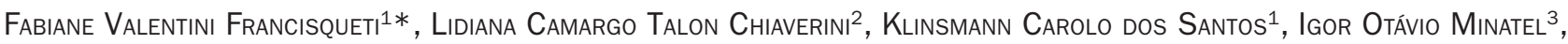
Carolina Berchieri Ronchi ${ }^{4}$, Artur Junio Togneri Ferron ${ }^{5}$, Ana Lúcia A. Ferreira ${ }^{6}$, Camila Renata Corrêa $^{7}$

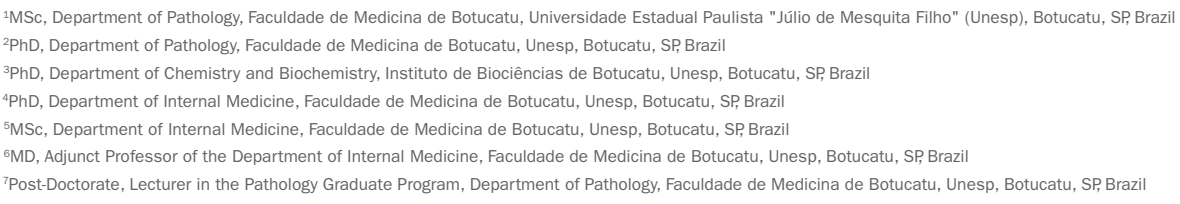

Study conducted at Faculdade de Medicina de Botucatu, Universidade Estadual Paulista "Júlio de Mesquita Filho" (Unesp), Botucatu, SP, Brazi

Article received: $3 / 9 / 2016$ Accepted for publication: 6/20/2016 *Correspondence: Address: Av. Prof. Montenegro Distrito de Rubião Junior, $\mathrm{s} / \mathrm{n}$ Botucatu, SP - Brazi

Postal code: $18618-970$ fabianevf@gmail.com

http://dx.doi.org/10.1590/1806-9282.63.01.85

\section{SUMMARY}

Metabolic syndrome (MetS) has a high prevalence around the world. Considering the components used to classify MetS, it is clear that it is closely related to obesity. These two conditions begin with an increase in abdominal adipose tissue, which is metabolically more active, containing a greater amount of resident macrophages compared to other fat deposits. Abdominal adiposity promotes inflammation and oxidative stress, which are precursors of various complications involving MetS components, namely insulin resistance, hypertension and hyperlipidemia. One way to block the effects of oxidative stress would be through the antioxidant defense system, which offsets the excess free radicals. It is known that individuals with metabolic syndrome and obesity have high consumption of fats and sugars originated from processed foods containing high levels of sodium as well as low intake of fruits and vegetables, thus maintaining a state of oxidative stress, that can speed up the onset of MetS. Healthy eating habits could prevent or delay MetS by adding antioxidant-rich foods into the diet.

Keywords: oxidative stress, metabolic syndrome, obesity.

\section{INTRODUCTION}

Metabolic syndrome (MetS), also known as syndrome $\mathrm{X}$ or insulin resistance syndrome, is characterized by the clustering of cardiovascular risk factors such as hypertension, insulin resistance, central obesity, and atherogenic dyslipidemia (high LDL-cholesterol, high triglycerides, and low HDL-cholesterol). ${ }^{1}$ MetS is a major health issue of westernized modern societies ${ }^{1}$ and it already appears as one of the main challenges of current clinical practice. In general, the International Diabetes Federation (IDF) estimates that one-quarter of the world's adult population has MetS and the observed prevalence of MetS in National Health and Nutrition Examination Survey (NHANES) was $5 \%$ among the subjects of normal weight, $22 \%$ among the overweight, and $60 \%$ among the obese. ${ }^{2}$

For the diagnosis of MetS, there are at least three criteria based on five components: waist circumference, blood pressure, blood glucose, triglycerides, and HDL-cholesterol. The National Cholesterol Education Program - Adult Treatment Pannel III (NCEP - ATP III) ${ }^{3}$ adopts at least three components for diagnosis of MetS. The $\mathrm{IDF}^{4}$ considers the abdominal circumference and two more components, and the World Health Organization (WHO) ${ }^{5}$ uses the waist/hip ratio, presence of type 2 diabetes mellitus (DM) or insulin resistance, microalbuminuria, hypertension and triglycerides.

Observing the components that classify the individual as having metabolic syndrome, it can be noted that they are all complications that commonly affect obese individuals, which shows that there is a direct link between these two diseases. ${ }^{6}$ In general, these two conditions begin to increase in abdominal adipose tissue which is more metabolically active, containing a higher amount of resident macrophages compared to other fat deposits. ${ }^{7} \mathrm{Ab}-$ dominal adiposity promotes inflammation and oxidative 
stress, which are precursors of various complications involving MetS components, namely insulin resistance, hypertension, and hyperlipidemia (Figure 1) ${ }^{8,9}$ Because MetS is associated with cardiovascular complications, the main cause of death worldwide, it is important to understand the factors that are involved in this disorder. Thus, this review aims to present the involvement of oxidative stress in the onset of metabolic syndrome.

\section{Metabolic syndrome and oxidative StRess}

Inflammation and oxidative stress occur when the energy supply begins to exceed the storage capacity of adipocytes and, as a result, hypertrophy occurs. ${ }^{10}$ This hypertrophy leads to a higher release of adipokines as proinflammatory cytokines such as interleukin-1 (IL-1), interleukin-6 (IL-6) and tumor-necrosis factor alpha (TNF- $\alpha$ ), resulting in low-grade chronic inflammation, which begins in adipose tissue and eventually reaches the circulation and other organs. ${ }^{11,12}$ One of the first consequences of inflammation is insulin resistance, since TNF- $\alpha$ prevents the phosphorylation of insulin receptors, interfering in their cascade action and preventing their functioning. ${ }^{13}$ Insulin resistance and type 2 diabetes mellitus are classically characterized by dyslipidemia with hypertriglyceridemia, low HDL-cholesterol and LDL-cholesterol appearance. ${ }^{14}$ In- sulin resistance decreases insulin function, leading to a change in storage lipids that is a mechanism dependent on this hormone..$^{15}$

Another cause of inflammation is oxidative stress, which can be triggered by adipocytes. When fat mass increases, insufficient irrigation can lead to lack of oxygen and, thus, to cell necrosis. The process of phagocytosis to eliminate these dead cells results in increased inflammatory infiltration and also oxidative stress by liberation of free radicals such as nitric oxide and hydrogen peroxide, ${ }^{16,17}$ which may negatively impact components of MetS. ${ }^{18}$

Oxidative stress is classically defined as an event resulting from the magnitude of imbalance between oxidant and antioxidant substances, ${ }^{19,20}$ generated in a setting of oxidation-reduction reactions. Since the generation and the action of these substances depend on this oxidation-reduction system, authors now use the term "imbalance of redox system" to refer to the oxidative stress. ${ }^{21,22} \mathrm{Com}$ monly known as free radicals, oxidants include reactive oxygen and nitrogen species, which perform the oxidation of lipids (lipoxidation) and glucose (glycation), substances found in excess in obesity. Excessive food intake increases the amount of energy and nutrients in the blood stream..$^{23}$ Lipoxidation products include malondialdehyde, glyoxal, acrolein, 4-hydroxy-nonenal (HNE), while the

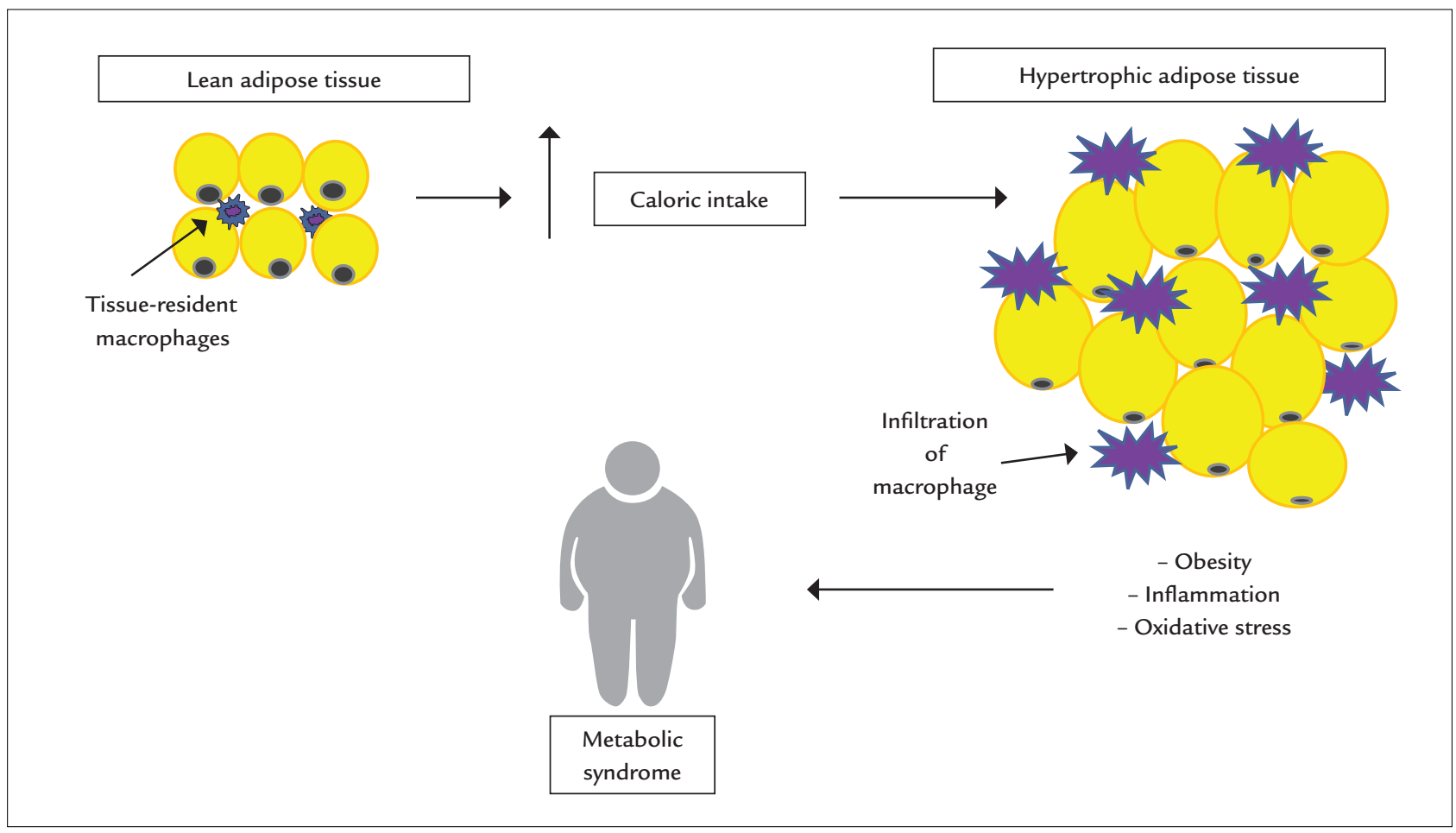

FIGURE 1 Excessive calorie intake leads to hypertrophy of adipose tissue and increased macrophage infiltration, a condition which favors inflammation and oxidative stress situations: a precursor of the metabolic syndrome. 
products generated from glycation include glyoxal and methyl glyoxal. These compounds bind to the amino grouping of amino acids, resulting in advanced glycation end-products (AGEs) and advanced lipoxidation end-products (ALEs), ${ }^{24}$ which are highly reactive and participate in the development of other components of MetS.

Clinical studies in patients with hypertension showed that systolic and diastolic blood pressure are positively correlated with biomarkers of oxidative stress and negatively correlated with the levels of antioxidants..$^{25-27}$ This fact is attributed to endothelial dysfunction caused by oxidative stress and inflammation, producing imbalance of vasoconstrictor and vasodilator products. This is evidenced by an inverse association between factors that trigger vasodilation, plasma levels of malondialdehyde and positive association with antioxidants. ${ }^{28}$

Oxidative stress plays an important role on the pathogenesis of insulin resistance by disrupting the release of adipokines by adipose tissue such as TNF- $\alpha$ and IL- 6 , which can trigger inflammation, a mechanism already described above. ${ }^{29-31}$ Thus, it seems that obesity and MetS are factors associated to inflammation and oxidative stress.

\section{Antioxidant defense}

Oxidative stress is controlled by the endogenous antioxidant defense system, which includes antioxidant enzymes such as superoxide dismutase, catalase, glutathione peroxidase, glutathione reductase; and nonenzymatic compounds such as ferritin, transferrin, bilirubin, ceruloplasmin, and even albumin carrier low molecular weight, such as uric acid and lipoic acid. ${ }^{32}$ Exogenous antioxidants from fruits and vegetables, including hydrophilic as vitamin C and flavonoids and lipophilic as vitamin $\mathrm{E}$ and carotenoids, are also included. Carotenoids are divided into a group of pigments that give yellow and orange colors to plants, animals, and microorganisms. More than 700 carotenoids have been identified; however, lutein, zeaxanthin, cryptoxanthin, alpha-carotene, beta-carotene, and lycopene represent $95 \%$ of the carotenoids in human plasma. ${ }^{33}$

Antioxidants are able to trap free radicals generated by cellular metabolism or exogenous sources through the donation of hydrogen atoms of these molecules, breaking the chain reaction, which prevents attack on lipids, amino acids in proteins, double bond of the polyunsaturated fatty acids, and DNA bases, avoiding formation of lesions and loss of cell integrity. ${ }^{34}$ Another role of antioxidants is the protection mechanism, which acts in the repair of damage caused by free radicals, a process related to the removal of the DNA molecule of damage and restoration of damaged cell membranes. ${ }^{35}$
The literature reports that a diet rich in fruits, vegetables and grains prevents various diseases, such as cardiovascular diseases and cancer. ${ }^{36,37}$ Other intervening factor in antioxidant response and the manifestations of MetS is the association between dietary adequacy and physical exercise. ${ }^{38}$ This is due to the exogenous and endogenous antioxidants acting in synergy in combating free radicals. ${ }^{25}$ However, it is important to note that this intake needs to be steady and orderly and that the intake of vitamins in supplement form may result in pro-oxidant effects called stress antioxidative. ${ }^{39}$

\section{BIOMARKERS OF OXIDATIVE STRESS}

The reactive species are very unstable and have a very short half-life, which makes it a major challenge to perform an accurate assessment of these species. For this reason, methods have been developed for measuring products resulting from the redox markers in biological samples, which are oxidation products of lipids, DNA and proteins. ${ }^{40}$ Among the most common are the products of lipid peroxidation because of polyunsaturated fatty acids (such as phospholipids and glycolipids). When these lipids are oxidized, two products classically measured in biological samples, malondialdehyde (MDA) and isoprostan, are formed. . $^{40,41}$

MDA is formed by the peroxidation of polyunsaturated fatty acids and can interact with proteins. MDA can be detected by the thiobarbituric acid (TBA) using a colorimetric method based on MDA TBA reaction and form a pink color, so gauging MDA and all species reacting with this acid. ${ }^{42}$ The MDA can be specifically measured by high performance liquid chromatography (HPLC). The same reaction occurs between MDA and TBA, but due to the apparatus of the fluorescence detector, only the MDA is identified, making this more specific test. ${ }^{43}$

The isoprostane is a stable product of lipid peroxidation, and can be measured both in the tissues and in biological fluids including urine, plasma, and cerebrospinal fluid. The level of this compound in plasma and urine correlates with the levels of reactive oxygen species and oxidative stress in experimental studies in humans. ${ }^{44}$ However, in healthy individuals at risk for obesity and hyperlipidemia their levels are increased, suggesting it as a good marker for cardiovascular risk. ${ }^{41}$

Total antioxidant capacity can be considered a marker of oxidative stress, since it measures the state of antioxidant capacity in biological fluids. This method gives deeper insight into the involvement of oxidative stress in several pathophysiological conditions, but also monitors the effectiveness of antioxidant interventions ${ }^{44}$ In this method the antioxidant capacity of the sample is quanti- 
fied by comparing the area under the curve (AUC) on the oxidation kinetics of BODIPY (4,4-difluoro-1,3,5,7,8pentamethyl-4-bora-3a, 4a-diaza-s-indacene), a fluorescent lipophilic oxidizable compound, radical initiator opposite 2.20 azobis- (2-amidinopropane) dihydrochloride (AAPH) in relation to the oxidation of phosphatidylcholine used as a reference lipid matrix. ${ }^{45}$

Another approach to assess the antioxidant capacity is to measure antioxidants individually. However, as there are many, this would require time and a variety of analytical techniques, instruments, and procedures. In addition, this approach lacks information about the possible synergy and cooperation between the hydrophilic and lipophilic antioxidants. ${ }^{45}$

Protein and DNA molecules are also highly susceptible to modification by changes in redox state. ${ }^{46}$ The protein oxidation occurs when proteins of amino acids (proline, arginine, threonine, lysine, histidine and cysteine) bind to glycoxidation and lipoxidation products, forming carbonyl groups. This reaction called carbonylation may be irreversible and lead to changes in their biological function; the detection of these toxic products (carbonyl) can be made by the mass spectrometer. ${ }^{24}$

As for DNA damage, comet assay can be performed, a cell microgel electrophoresis technique, very useful and widely used to assess damage and DNA repair in individual cells. Its basic principle is the lysis of cell membranes, followed by induction of DNA released from the electrophoretic migration on agarose matrix. When viewed under a microscope, the migrated cell takes the apparent form of a comet, with a head, the nuclear region, and a tail, which contains fragments or DNA strands that have migrated towards the anode. The analysis of comets is based on the degree of DNA fragmentation and migration by microelectrophoresis. ${ }^{47}$ Measures such as the total length of the "tail" and the DNA density provide indirect information about the state of the sample DNA. To detect oxidative damage, endonuclease III (ENDOIII) and phosphatidylinositol-pyrimidine DNA glycosylase (FPG) are used to repair enzyme thus detecting oxidation bases in the pyrimidine and purine. ${ }^{48}$

\section{DIETARY INTAKE, PHYSICAL ACTIVITY, OXIDATIVE STRESS, AND METABOLIC SYNDROME}

According to what has been previously described, it is clear that when there is an imbalance within a large supply of nutrients and a low antioxidant intake, obesity carries a picture of oxidative stress promoting metabolic syndrome. ${ }^{23}$ Corroborating this fact, the literature indicates that individuals with metabolic syndrome and obe- sity have a high consumption of fat and sugars derived from processed foods with high sodium content, ${ }^{49-51}$ as well as low antioxidant intake.

Diets with high antioxidant content, such as the well-known Mediterranean diet, which consists of olive oil, fruits and vegetables, cereals, nuts, and a small amount of red meat and foods high in sugar, are also ways to manage oxidative stress and inflammation. ${ }^{52,53}$ Researchers suggest that individuals with MetS and obesity delayed and attenuated complications, such as insulin resistance, hypertension, and hyperlipidemia, when they had an intervention and began to consume this type of diet. One of the arrangements set out for this improvement was the reduction of oxidative stress and inflammation. ${ }^{53-57}$

Among these studies, Mitjavila et al. ${ }^{58}$ observed a decrease of some markers of oxidative stress after one year of dietary intervention. In this same study, subjects with MetS who consumed the Mediterranean diet were compared to a group that consumed a diet with only low levels of fat. It showed that a diet richer in antioxidants resulted in improvement in markers of oxidative stress and decreased DNA damage. This shows the importance of diet quality and the consistency and effectiveness of antioxidants in its composition.

Another factor associated to MetS is reduced daily physical activity in healthy young adults, which leads to negative metabolic consequences such as decreased insulin sensitivity and increased abdominal fat. ${ }^{59}$ Therefore, increased physical activity is likely to be the evolutionary favored pathway to prevent the development of insulin resistance during metabolic derangements. The impact of exercise on insulin sensitivity is evident for 24 to 48 hours and disappears within 3 to 5 days, so continuous practice is essential. ${ }^{2}$ Besides, exercise increases the production of oxidative stress. However, these increases seem to be necessary in order to allow for an upregulation in endogenous antioxidant defenses, thus providing beneficial effects to the individual engaged in chronic exercise. ${ }^{60}$ A combination of resistance and aerobic exercise is the best, but any activity is better than none.

The association between good eating habits and exercise practice is also important. A recent study showed that food adequacy (intake of fruits and vegetables) associated with physical exercise for 20 weeks resulted in higher cardiorespiratory fitness in residents of the city of Botucatu, SP. Moreover, reduction in visceral adiposity (waist circumference) was observed, reducing the prevalence of MetS and mainly increasing significantly glutathione concentration and total antioxidant protection (TAP) of the plasma. ${ }^{38}$ Dietary caloric restriction as well as aerobic exercise, an- 
aerobic exercise, and resistance training in association with weight loss has been shown to be advantageous in ameliorating oxidative stress and alleviating inflammation in obesity. Studies report that healthy obese patients doing exercise showed decreased lipid peroxidation indicator. ${ }^{61-63}$ Thus, it is important to consider strategies that increase the antioxidant defense capacity of the body, since the same part not only of detoxification of free radicals, but are also closely related to modulation of pathophysiologic processes present in the MetS (Figure 2).

\section{Final considerations}

This review's approach can highlight the involvement of inflammation, and especially oxidative stress, in the pathogenesis of MetS. Given that obesity may be a key event in the development of this syndrome, treatment strategies are necessary to control and attenuate oxidative stress so that the body does not develop complications leading to MetS.

One of the main factors triggering these two pathologies is food imbalance. In recent decades, there has been an increase in the intake of sugars and fats parallel to a reduction of the consumption of fruit and vegetables; this alone promotes oxidative stress and has been the root cause in the growing epidemic of chronic diseases that affect developed and developing countries. A decrease in food intake coupled with physical activity would be a determining factor in the reduction of oxidative stress. The excess calories from sugar and fat intake, combined with a sedentary lifestyle, cause the body to manage the excess energy that must be metabolized. Other macronutrients undergo oxidation within the mitochondria, promoting an increase in production of free radicals, which has been proposed as a unifying mechanism linking excessive intake of nutrients, insulin resistance, metabolic syndrome, and diabetes. Therefore, what could prevent or delay the onset of MetS would be the maintenance of healthy eating habits, with the inclusion of foods rich in antioxidants and physical activity.

\section{AckNOWLEDGment}

Thomas Patrick Wisniewski, Krupp Foundation Research Fellow, Harvard University.

\section{Conflict of InTERest}

The authors declare no conflict of interest.

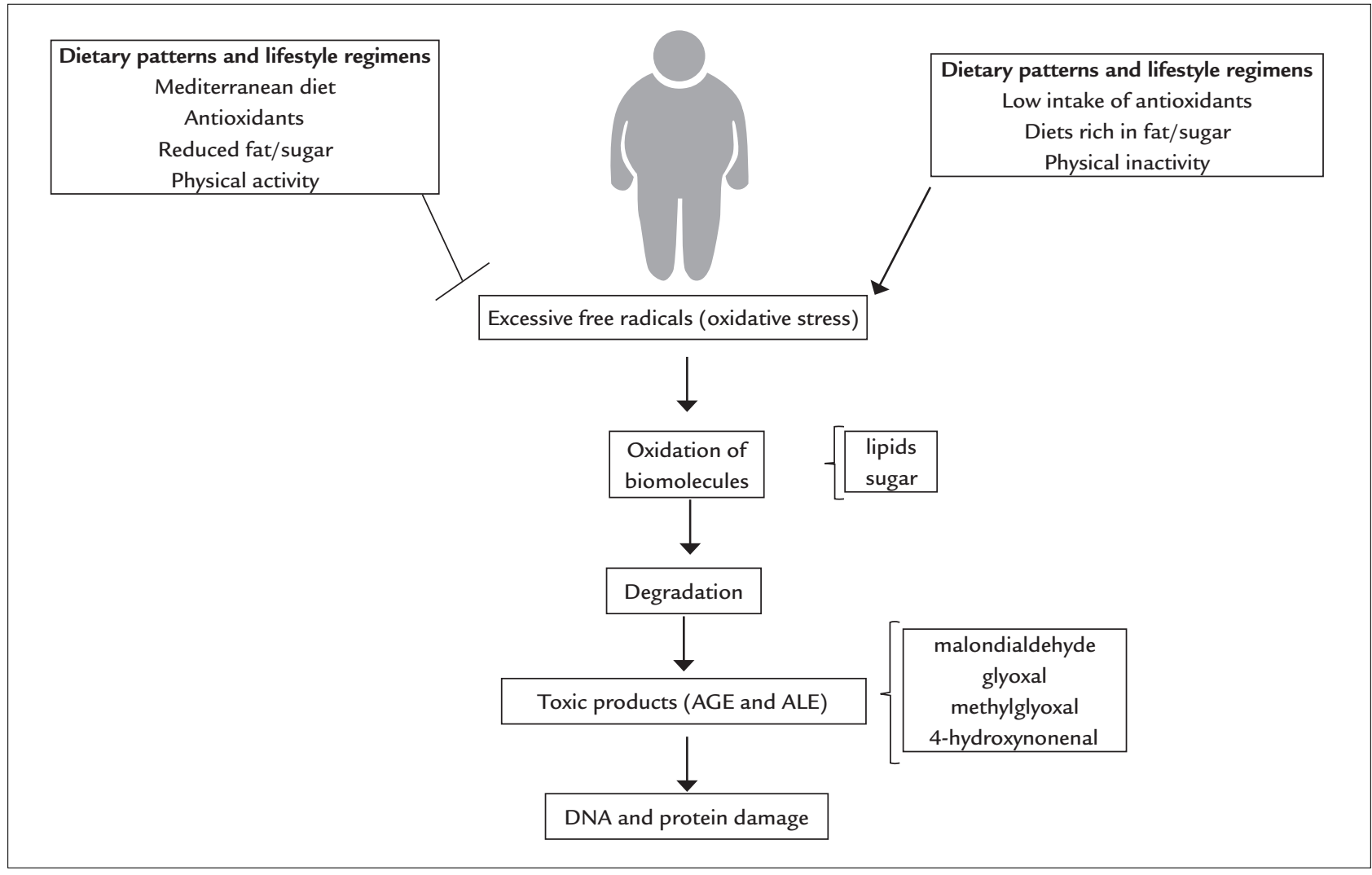

FIGURE 2 Biochemical way of oxidative stress.

AGE: advanced glycation end-products; ALE: advanced lipoxidation end-products. 


\section{Resumo}

O papel do estresse oxidativo na fisiopatologia da síndrome metabólica

A síndrome metabólica apresenta elevada prevalência na população mundial. De acordo com os componentes que a classificam, nota-se que está intimamente relacionada com a obesidade. Essas duas condições se iniciam com o aumento do tecido adiposo abdominal, o qual é metabolicamente mais ativo, contendo uma quantidade maior de macrófagos residentes em comparação com outros depósitos de gordura. Essa situação favorece a inflamação e o estresse oxidativo, ambos precursores de diversas complicações, mas principalmente as envolvidas na síndrome metabólica, como resistência à insulina, hipertensão arterial e hiperlipidemia. Uma maneira de bloquear os efeitos do estresse oxidativo seria pelo sistema de defesa antioxidante, o qual anula os radicais livres em excesso. É sabido que indivíduos portadores de síndrome metabólica e obesos apresentam um alto consumo de gorduras, açúcares oriundos de alimentos industrializados com alto teor de sódio e uma baixa ingestão de frutas e verduras, apresentando uma condição de estresse oxidativo contínuo. A manutenção de hábitos alimentares saudáveis, com a inclusão de alimentos ricos em antioxidantes, poderia prevenir ou retardar o surgimento da SM.

Palavras-chave: estresse oxidativo, síndrome metabólica, obesidade.

\section{References}

1. Steckhan N, Hohmann CD, Kessler C, Dobos G, Michalsen A, Cramer H Effects of different dietary approaches on inflammatory markers in patientes with metabolic syndrome: a systematic review and meta-analysis. Nutrition. 2016; 32(3):338-48.

2. Kaur J. A comprehensive review on metabolic syndrome. Cardiol Res Pract. 2014; 2014:943162.

3. Expert Panel on Detection, Evaluation, and Treatment of High Blood Cholesterol in Adults. Executive Summary of The Third Report of The National Cholesterol Education Program (NCEP) Expert Panel on Detection, Evaluation, And Treatment of High Blood Cholesterol In Adults (Adult Treatment Panel III). JAMA. 2001; 285(19):2486-97.

4. Alberti KG, Zimmet P, Shaw J; IDF Epidemiology Task Force Consensus Group. The metabolic syndrome - a new worldwide definition. Lancet. 2005; 366(9491):1059-62.

5. World Health Organization (WHO). Diet, nutrition and the prevention of chronic diseases. Geneva: WHO/FAO Expert consultation on diet, nutrition and the prevention of chronic diseases; 2002.

6. Dupuy AM, Jaussent I, Lacroux A, Durant R, Cristol JP, Delcourt C. Waist circumference adds to the variance in plasma C-reactive protein levels in elderly patients with metabolic syndrome. Gerontology. 2007; 53(6):329-39.

7. Luna-Luna M, Medina-Urrutia A, Vargas-Alarcón G, Coss-Rovirosa F, VargasBarrón J, Pérez-Méndez O. Adipose tissue in metabolic syndrome: onset and progression of atherosclerosis. Arch Med Res. 2015; 46(5):392-407.
8. Yao L, Herlea-Pana O, Heuser-Baker J, Chen Y, Barlic-Dicen J. Roles of the chemokine system in development of obesity, insulin resistance, and cardiovascular disease. J Immunol Res. 2014; 2014:181450.

9. Francisqueti FV, Nascimento AF, Corrêa CR. Obesidade, inflamação e complicações metabólicas. Nutrire. 2015; 40(1):81-9.

10. Klöting N, Blüher M. Adipocyte dysfunction, inflammation and metabolic syndrome. Rev Endocr Metab Disord. 2014; 15(4):277-87.

11. Cotillard A, Poitou C, Torcivia A, Bouillot JL, Dietrich A, Klöting N, et al. Adipocyte size threshold matters: link with risk of type 2 diabetes and improved insulin resistance after gastric bypass. J Clin Endocrinol Metab. 2014; 99(8):E1466-70.

12. Skurk T, Alberti-Huber C, Herder C, Hauner H. Relationship between adipocyte size and adipokine expression and secretion. J Clin Endocrinol Metab. 2007; 92(3):1023-33.

13. Andrade-Oliveira V, Câmara NOS, Moraes-Vieira PM. Adipokines as drug targets in diabetes and underlying disturbances. J Diabetes Res. 2015; 2015:681612.

14. Grundy SM. Hypertriglyceridemia, atherogenic dyslipidemia, and the metabolic syndrome. Am J Cardiol. 1998; 81(4A):18B-25B.

15. Borer KT. Counterregulation of insulin by leptin as key component of autonomic regulation of body weight. World J Diabetes. 2014; 5(5):606-29.

16. Bhattacharya I, Domínguez AP, Drägert K, Humar R, Haas E, Battegay EJ. Hypoxia potentiates tumor necrosis factor-alpha induced expression of inducible nitric oxide synthase and cyclooxygenase- 2 in white and brown adipocytes. Biochem Biophys Res Commun. 2015; 461(2):287-92.

17. Kosacka J, Kern M, Klöting N, Paeschke S, Rudich A, Haim Y, et al. Autophagy in adipose tissue of patients with obesity and type 2 diabetes. Mol Cell Endocrinol. 2015; 409:21-32.

18. Netzer N, Gatterer H, Faulhaber M, Burtscher M, Pramsohler S, Pesta D Hypoxia, oxidative stress and fat. Biomolecules. 2015; 5(2):1143-50.

19. Ferreira AL, Yeum KJ, Matsubara LS, Matsubara BB, Correa CR, Pereira EJ, et al. Doxorubicin as an antioxidant: maintenance of myocardial levels of lycopene under doxorubicin treatment. Free Radic Biol Med. 2007; 43(5):740-51.

20. Yeum KJ, Russell RM, Krinsky NI, Aldini G. Biomarkers of antioxidant capacity in the hydrophilic and lipophilic compartments of human plasma. Arch Biochem Biophys. 2004; 430(1):97-103.

21. Grant CM. Metabolic reconfiguration is a regulated response to oxidative stress. J Biol. 2008;7(1):1.

22. Poli G, Schaur RJ, Siems WG, Leonarduzzi G. 4-hydroxynonenal: a membrane lipid oxidation product of medicinal interest. Med Res Rev. 2008; 28(4):569-631.

23. Dandona P, Ghanim H, Chaudhuri A, Dhindsa S, Kim SS. Macronutrient intake induces oxidative and inflammatory stress: potential relevance to atherosclerosis and insulin resistance. Exp Mol Med. 2010; 42(4):245-53.

24. Aldini G, Dalle-Donne I, Facino RM, Milzani A, Carini M. Intervention strategies to inhibit protein carbonylation by lipoxidation-derived reactive carbonyls. Med Res Rev. 2007; 27(6):817-68.

25. Montezano AC, Dulak-Lis M, Tsiropoulou S, Harvey A, Briones AM, Touyz RM. Oxidative stress and human hypertension: vascular mechanisms, biomarkers, and novel therapies. Can J Cardiol. 2015; 31(5):631-41.

26. Wong WT, Tian XY, Huang Y. Endothelial dysfunction in diabetes and hypertension: cross talk in RAS, BMP4, and ROS-dependent COX-2-derived prostanoids. J Cardiovasc Pharmacol. 2013; 61(3):204-14.

27. Hernanz R, Briones AM, Salaices M, Alonso MJ. New roles for old pathways? A circuitous relationship between reactive oxygen species and cyclo-oxygenase in hypertension. Clin Sci (Lond). 2014; 126(2):111-21.

28. Ward NC, Hodgson JM, Puddey IB, Mori TA, Beilin LJ, Croft KD. Oxidative stress in human hypertension: association with antihypertensive treatment, gender, nutrition, and lifestyle. Free Radic Biol Med. 2004; 36(2):226-32.

29. Tangvarasittichai S. Oxidative stress, insulin resistance, dyslipidemia and type 2 diabetes mellitus. World J Diabetes. 2015; 6(3):456-80.

30. Houstis N, Rosen ED, Lander ES. Reactive oxygen species have a causal role in multiple forms of insulin resistance. Nature. 2006; 440:944-8.

31. Hotamisligil GS. Inflammation and metabolic disorders. Nature. 2006; 444(7121):860-7

32. Poljsak B, Šuput D, Milisav I. Achieving the balance between ROS and antioxidants: when to use the synthetic antioxidants. Oxid Med Cell Longev. 2013; 2013:956792.

33. Maiani G, Castón MJ, Catasta G, Toti E, Cambrodón IG, Bysted A, et al. Carotenoids: actual knowledge on food sources, intakes, stability and 
bioavailability and their protective role in humans. Mol Nutr Food Res. 2009; 53(Suppl 2):S194-218.

34. Sies H. Strategies of antioxidant defense. Eur J Biochem 1993; 215(2):213-9.

35. Sies H. Oxidative stress: from basic research to clinical application. Am J Med. 1991; 91(3C):31S-8S.

36. Mangge H, Becker K, Fuchs D, Gostner JM. Antioxidants, inflammation and cardiovascular disease. World J Cardiol. 2014; 6(6):462-77.

37. Fiedor J, Burda K. Potential role of carotenoids as antioxidants in human health and disease. Nutrients. 2014; 6(2):466-88.

38. Moreto F, Kano HT, Torezan GA, de Oliveira EP, Manda RM, Teixeira O, et al. Changes in malondialdehyde and C-reactive protein concentrations after lifestyle modification are related to different metabolic syndromeassociated pathophysiological processes. Diabetes Metab Syndr. 2015; 9(4):218-22.

39. Niki E. Biomarkers of lipid peroxidation in clinical material. Biochim Biophys Acta. 2014; 1840(2):809-17

40. Petramala L, Pignatelli P, Carnevale R, Zinnamosca L, Marinelli C, Settevendemmie A, et al. Oxidative stress in patients affected by primary aldosteronism. J Hypertens. 2014; 32(10):2022-9; discussion 2029.

41. Basu S. Bioactive eicosanoids: role of prostaglandin $\mathrm{F}$ (2alpha) and $\mathrm{F}(2)$ isoprostanes in inflammation and oxidative stress related pathology. Mol Cells.; 30(5):383-91.

42. Reis GS, Augusto VS, Silveira AP, Jordão AA Jr, Baddini-Martinez J, Poli Neto $\mathrm{O}$, et al. Oxidative-stress biomarkers in patients with pulmonary hypertension. Pulm Circ. 2013; 3(4):856-61.

43. Davies SS, Roberts LJ 2nd. F2-isoprostanes as an indicator and risk factor for coronary heart disease. Free Radic Biol Med. 2011; 50(5):559-66.

44. Fraga CG, Oteiza PI, Galleano M. In vitro measurements and interpretation of total antioxidant capacity. Biochim Biophys Acta. 2014; 1840(2):931-4.

45. Beretta G, Aldini G, Facino RM, Russell RM, Krinsky NI, Yeum KJ. Total antioxidant performance: a validated fluorescence assay for the measurement of plasma oxidizability. Anal Biochem. 2006; 354(2):290-8.

46. Shacter E. Quantification and significance of protein oxidation in biological samples. Drug Metab Ver. 2000; 32(3-4):307-26.

47. Prado RP, dos Santos BF, Pinto CL, de Assis KR, Salvadori DM, Ladeira MS. Influence of diet on oxidative DNA damage, uracil misincorporation and DNA repair capability. Mutagenesis. 2010; 25(5):483-7.

48. Collins AR, Gedik CM, Olmedilla B, Southon S, Bellizzi M. Oxidative DNA damage measured in human lymphocytes: large differences between sexes and between countries, and correlations with heart disease mortality rates. FASEB J. 1998; 12(13):1397-400.

49. Novak EM, Keller BO, Innis SM. Dietary lipid quality and long-term outcome. Nestle Nutr Workshop Ser Pediatr Program. 2011; 68:17-27; discussion 27-32.
50. Johnson RJ, Nakagawa T, Sanchez-Lozada LG, Shafiu M, Sundaram S, Le $\mathrm{M}$, et al. Sugar, uric acid, and the etiology of diabetes and obesity. Diabetes. 2013; 62(10):3307-15.

51. Keller U. Dietary proteins in obesity and in diabetes. Int J Vitam Nutr Res. $2011 ; 81(2-3): 125-33$

52. Castro-Quezada I, Román-Viñas B, Serra-Majem L. The Mediterranean diet and nutritional adequacy: a review. Nutrients. 2014; 6(1):231-48.

53. Casas R, Sacanella E, Estruch R. The immune protective effect of the Mediterranean diet against chronic low-grade inflammatory diseases. Endocr Metab Immune Disord Drug Targets. 2014; 14(4):245-54.

54. Kastorini CM, Milionis HJ, Esposito K, Giugliano D, Goudevenos JA Panagiotakos DB. The effect of Mediterranean diet on metabolic syndrome and its components: a meta-analysis of 50 studies and 534,906 individuals J Am Coll Cardiol. 2011; 57(11):1299-313.

55. Salas-Salvadó J, Bulló M, Babio N, Martínez-González MÁ, Ibarrola-Jurado $\mathrm{N}$, Basora J, et al. Reduction in the incidence of type 2 diabetes with the Mediterranean diet: results of the PREDIMED-Reus nutrition intervention randomized trial. Diabetes Care. 2011; 34(1):14-9.

56. Doménech M, Roman P, Lapetra J, García de la Corte FJ, Sala-Vila A, de la Torre R, et al. Mediterranean diet reduces 24-hour ambulatory blood pressure, blood glucose, and lipids: one-year randomized, clinical trial. Hypertension. 2014; 64(1):69-76.

57. Vincent-Baudry S, Defoort C, Gerber M, Bernard MC, Verger P, Helal O, et al. The Medi-RIVAGE study: reduction of cardiovascular disease risk factors after a 3-mo intervention with a Mediterranean-type diet or a low-fat diet. Am J Clin Nutr. 2005; 82(5):964-71.

58. Mitjavila MT, Fandos M, Salas-Salvadó J, Covas MI, Borrego S, Estruch R, et al. The Mediterranean diet improves the systemic lipid and DNA oxidative damage in metabolic syndrome individuals. A randomized, controlled, trial. Clin Nutr. 2013; 32(2):172-8.

59. Golbidi S, Mesdaghinia A, Laher I. Exercise in the metabolic syndrome. Oxid Med Cell Longev. 2012; 2012:349710.

60. Huang CJ, McAllister MJ, Slusher AL, Webb HE, Mock JT, Acevedo EO Obesity-related oxidative stress: the impact of physical activity and diet manipulation. Sports Med Open. 2015; 1:32.

61. Phillips MD, Patrizi RM, Cheek DJ, Wooten JS, Barbee JJ, Mitchell JB. Resistance training reduces subclinical inflammation in obese, postmenopausal women. Med Sci Sports Exerc. 2012; 44(11):2099-110.

62. Oh S, Tanaka K, Warabi E, Shoda J. Exercise reduces inflammation and oxidative stress in obesity-related liver diseases. Med Sci Sports Exerc. 2013; 45(12):2214-22.

63. Shin YA, Lee JH, Song W, Jun TW. Exercise training improves the antioxidant enzyme activity with no changes of telomere length. Mech Ageing Dev. 2008; 129(5):254-60. 